\begin{tabular}{lc}
\hline ISSN: & Joumal of \\
Print $-2277-078 \mathrm{X}$ & Humanities, Social \\
Online $-2315-747 \mathrm{X}$ & Sciences and Creative \\
O UNAAB 2017 & Arts \\
\hline
\end{tabular}

\title{
IMPACT OF TEAM WORK ON TERTIARY INSTITUTION PERFORMANCE: A STUDY OF SELECTED COLLEGES IN FUNAAB
}

\author{
10. 0. OYEDELE AND 2K. A. MALIK \\ *1D epartment of Entrepreneurial Studies, Federal University of Agriculture, Abeokuta, \\ Nigeria \\ 2Lyceum College, O gun State, Nigeria. \\ *Comesponding Author: olacollins2014@gmail.com
}

\begin{abstract}
Successful teamwork is being recognized as a necessity for many aspects of effective administrative assignments and team-leadership has proved effective in improving team performance. Using two management-related colleges of Federal University of Agriculture, Abeokuta (FUNAAB) as organization of study, ninety respondents were sampled through the use of questionnaire. It was concluded after analysis that the practice of team-working is and should be embraced by corporate organizations, especially tertiary institution i.e. the more collectively engaged staff members are, the better the outcomes for the organization generally. Likewise it was also concluded that working in well-structured teams with an effective team-leader is a predictors of both individual and collective performance. The recommendation among others was that other institutions (private/ public) in the education sector should emulate the FUNAAB team-working initiative in order to continually and effectively meet their corporate obligations.
\end{abstract}

Keywords: teamwork, team-leadership, and FUNAAB

\section{INTRODUCTION}

Teamwork is as old as mankind, and as such many organisations use the term 'team' in either one sense or the other i.e. such as in the production team, marketing team, management or administrative team, or the entire organisation can be referred to as a team. Davis et al (2007) claimed that, employers always stress the need for employing those (employees) that are able to work with a team. And they (employers) generally talk of teamwork when they want to emphasize the need to various talents possessed by different employees. Organisations however, coordinate the employees into different teams, such as management team, production team, maintenance team etc. This is purposely to tap from the abilities of respective human resources employed by an organisation.

1. Team work is the ability to work together towards a common vision. It is a fuel that allows common people to attain uncommon results. Collective action is widely recognized as a positive force for teamwork in any organisation or institution to succeed.

2. Teams enable individuals to empower themselves and to increase benefits from 


\section{O. O. OYEDELE AND K. A. MALIK}

cooperative work engaged on as a group. G etting together with others also can allow individuals to better understand the importance of teamwork and how the Organisations operate as well as promote the culture of teamwork success. Alan (2003) defined teamwork as a grouping of professionals whose members work intensely on a specific, common goal using their positive synergy, individual and mutual accountability, and complementary skills.

\section{O bjectives of the Study}

The main objective of the study is to investigate the contributions of teamwork on organisational performance. The study will also:

1. (i). find out the effect of teamwork on institutional performance.

2. (ii). find out the effect of teamleadership on team performance.

\section{$H$ ypotheses}

1. To attain the objective of this research, the following hypotheses were formulated.

2. H01: Teamwork does not affect institutional performance

3. H02: There is no significant relationship between team-leadership and team performance.

\section{Review of Relevant L iterature}

1. Most commonly, teams are viewed as a three-stage system where they utilize resources (input), maintain internal processes (through put) and produce specific products (output). Analysis of antecedent conditions and team processes often highlight issues for team development and training. In contrast, outcomes (output) are generally used to judge or evaluate team effectiveness,
Mulika (2010).

The submission above indicates that the success of any team is a three-in-one process: right/ proper engagement, purposeful teaming, and clear cut achievements.

This tripartite analysis can be linked with the systems model of teamwork, where organisational structure and individual contributions refer to antecedent conditions (input) and team processes generally refer to throughput.

\section{Theoretical Framework}

1. Systems Theory

2. Social Action Theory

\section{Systems Theory}

Systems theory is the interdisciplinary study of systems. A system is an entity with interrelated and interdependent parts; it is defined by its boundaries and it is more than the sum of its parts (subsystem). Changing one part of the system affects other parts and the whole system, with predictable patterns of behavior. Positive growth and adaptation of a system depend upon how well the system is adjusted with its environment, and systems often exist to accomplish a common purpose (a work function) that also aids in the maintenance of the system or the operations may result in system failure. The goal of systems theory is systematically discovering a system's dynamics, constraints, conditions and elucidating principles (purpose, measure, methods, tools, etc.) that can be discerned and applied to systems at every level of nesting, and in every field for achieving optimized results (Wikipedia).

Systems theory has been proposed as a basis for the unification of science. Systems theory seems to provide a relief from the limitations of more mechanistic approaches and a rationale for rejecting "principles" based on 
relatively "closed-system" thinking. This theory provides the paradigm for organization and management theorists to "crank into their systems model" all of the diverse knowledge from relevant underlying disciplines. In the broadest conception, the term connotes a complex of interacting components together with the relationships among them that permit the identification of a boundary-maintaining entity or process (D urkheim 1984).

The knowledge of systems theory in the formulation (designing the sub-systems/ components, the synergy, the operation model, identification of boundaries, feedback mechanism and hierarchy structure, goals formulation and breakdown) and implementation can be used in organisations to ensure staff optimal utilization, engagement and team-working, that could in turn boost performance.

Figure 2.1 below depicts the linear nature of the system. There are inputs, outputs, and outcomes. However, what happens in the system is somewhat mysterious, and one can only measure the changes by observing the outputs in relationship to the outcomes or goals of the system. Workers can vary or modify the inputs, including their own actions, to create a change within the system. Assuming this model, the necessary antecedent conditions (input) together with the processes (through put) of maintaining teams define the characteristics of effective teams.

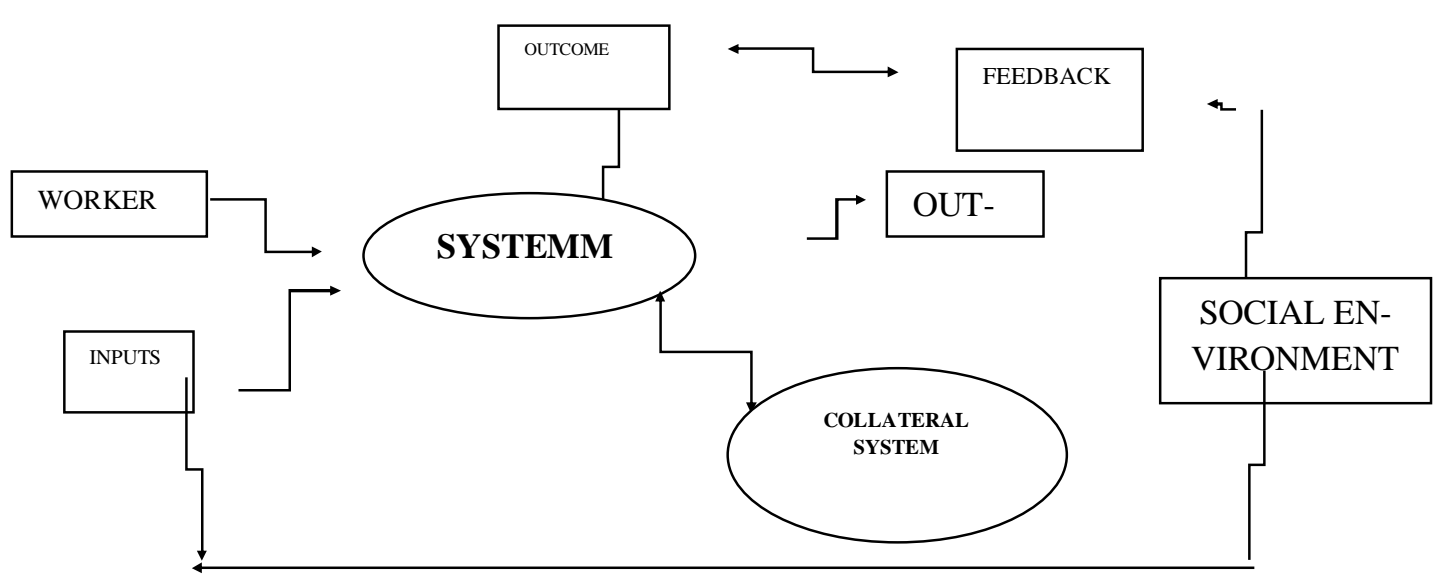

Figure 2.1 SYSTEMS MODEL

Source: D urkheim, 1984

\section{Social Action Theory}

The Social Action Theory is a communityoriented model that is used to increase the problem-solving ability of entire communities through achieving concrete changes towards social justice. That is, individuals within communities come together to re- dress the imbalance of powers or privileges between a disadvantaged group and society at large. The Social Action Theory applies key concepts that are used within many community-organizing and community-building models. These key concepts include empowerment, critical consciousness, community 


\section{O. O. OYEDELE AND K. A. MALIK}

capacity, social capital, issue selection, and participation and relevance (Max Weber, 1964)

\section{Conceptual framework \\ Employee engagement and commit- ment}

Commitment and engagement are closely related concepts. In fact, some people use the terms interchangeably or refer to engagement as an alternative, more up-to-date and, maybe, a more sophisticated term for commitment. The various definitions available of commitment and engagement do not help. TheOxford Engish Dictionary states that someone is committed when they are morally dedicated (to doctrine or cause), while someone is engaged when they are employed busily.

The meaning of organizational commitment as defined by Saks (2006) refers to attachment and loyalty. As closely as they go, employees will be more committed if they are well/ properly engaged.

\section{Engagement and Employee Involve ment}

Whilst some argue that employees are 'engaged' if they have a positive attitude towards work, others such as Purcell \& al, (2003) suggest that employee engagement is only meaningful if there is a more genuine sharing of responsibility between management and employees over issues of substance. The CIPD survey conducted by Truss \& al, (2006) suggests that strengthening employevicecan make a difference to organisational performance.

Employee voice can be defined as the ability for employees to have an input into decisions that are made in organisations (Lucas $\&$ al, 2006). It has been argued that one of the main drivers of employee engagement is for employees to have the opportunity to feed their view upwards (Truss \&al, 2006).

\section{Key attributes for successful teamwork}

- Commitment to team success and share goals

- Interdependence

- Interpersonal Skills

- Open communication and positive feed back

- Appropriate team composition

- Commitment to team processes, leader ship \& accountability

\section{“TERT” Model of Performance}

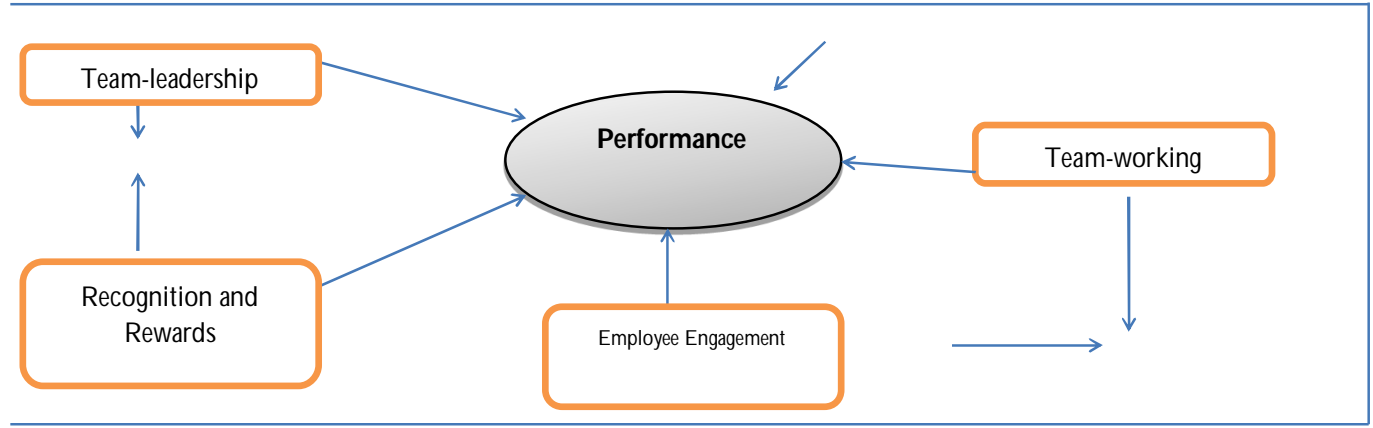

Based on the literature reviewed, the conceptual framework for the independent variables is acronym as "TE RT" Model of Performance.

Source: Researcher's initiative 


\section{Body of knowledge}

From happenings in the business world, having a large population of workers in an organisation does not totally depict a high tendency for performance and improvement. Many small organisations are breaking through more than most large ones. It may be as a result of the following problems:

Lack of teamwork in organisations: This means the failure of an organisation to coordinate works into work groups in order to tap from the respective human resources the organisation possesses.

Bad Team-leadership: Team-leadership of the work teams plays a vital role. Different work teams may exist, but lacking the persons with the team leading acumen to lead them could render the efforts of the team futile.

Under-performance of employees due to little or no proper engagement. Not engaging employees correctly (square peg in a round hole) may affect employees' morale to work, and it could in turn reduce their commitment and performance level.

From the literature reviewed, teamwork is a complex phenomenon. Supportive organisational structures and optimal individual contributions set the scene for effective teamwork. Furthermore, strategic planning processes can clarify the alignment of multiple teams within organisations.

Leadership styles and patterns need to be explicit and appropriate to the team's developmental stages. Ideally, the team leader should be appropriately skilled and all team members need clearly delineated and necessary roles.
Teams are more efficient with the minimum number of members to meet their purpose and membership should be regularly clarified in response to patient needs.

Team members must simultaneously recognize and value their contributions to the team. With sufficient self-knowledge, individuals can trust and respect the contributions of their colleagues. When individuals feel confident of the need for all team members, they understand the benefits of working as a team. Over time, commitment reinforces effective teamwork.

Once teams have developed clear structures, they need to maintain explicit processes through agreed and formal systems of communication and co-ordination. Consistent education and support for team building and development should be accessible for all workers. When all team members are cohesive, make decisions jointly and manage conflict, the team is more effective. Both individuals and the team need regular feedback and recognition of their progress towards the team's goals.

Finally, there is a need to build and maintain effective teams to maximize the specialist skills of professionals in meeting complex organizational needs. Team development and performance can be promoted through education as knowledge of the most important characteristics of team-working is vital for organizational and personal achievements.

\section{METHODOLOGY}

This research was carried out at Federal University of Agriculture, Abeokuta, O gun State 


\section{O. O. OYEDELE AND K. A. MALIK}

(FUNAAB). FUNAAB is one of the three Universities of Agriculture in Nigeria, the others being in Makurdi (Benue State) and Umudike (Abia State). It was established in January 1988.

The study was conducted to investigate the effect of teamwork on institutional performance. The data was collected from staff members of College of Management Sciences (COLMAS) and College of Agricultural Management and Rural Development COLAMRUD. Staff at both lower and upper levels of the two colleges constitutes the population for this study with fifty-one (51) and sixty-four (64) staff respectively. Hence, 115 staff has been ascertained as the popu- lation size of the study (www.unaab.edu.ng). In determining the sample size for this study, the following sampling technique formula was deployed.

$$
\begin{gathered}
\left.\mathrm{n}=\quad \begin{array}{l}
\mathrm{N} \\
\left(1+\mathrm{N}^{-}\right.
\end{array}\right), \quad \text { where } \mathrm{n}=\text { Sample size } \\
\mathrm{e}=\text { level of significance }(0.05)^{*}
\end{gathered}
$$

Hence, computing a population of 115 gives a sample size of 89. Therefore, a total of ninety (90) well-structured questionnaires were administered using simple random and convenient sampling (Dionco-Adetayo, 2011).

The study has the design of respondents as follows:

\section{Colleges}

COLMAS

COLAMRUD

TOTAL

\section{Anticipated respondents}

40

50

90
The reliability and validity of the questionnaire items gave a Cronbach's alpha of 0.76 . Out of the 90 questionnaires distributed, 79 duly filled questionnaires were recovered, giving $88 \%$ return rate. The research study used SPSS for analysis. The main sources of secondary sources were journals, articles, and research textbooks. 


\section{Data Presentation and Analysis}

Table1: Demographic data

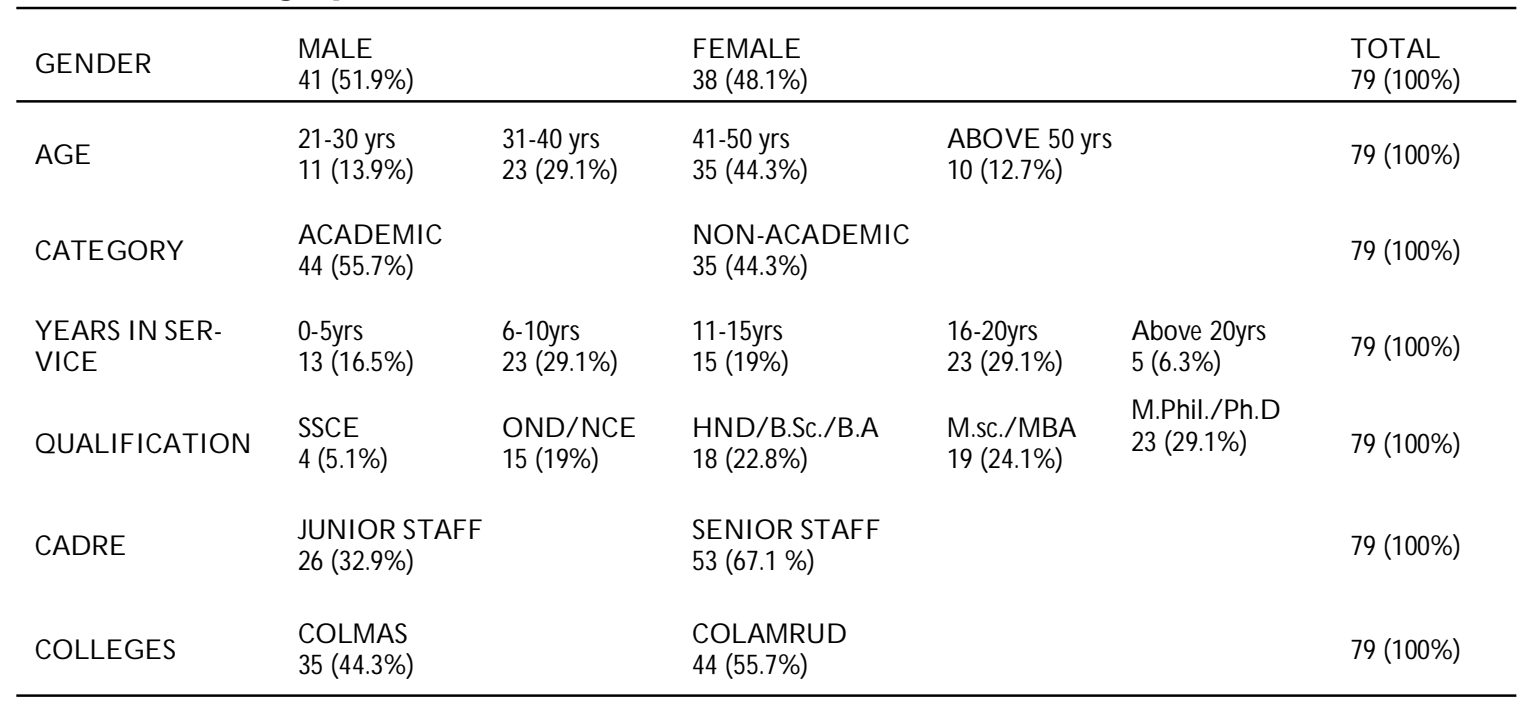

\section{Test of Hypothesis}

H0: Teamwork does not affect institutional performance

Hi: Teamwork does affect institutional performance

Test Statistics

Teamwork and performance

Chi-Square

$55.734 \mathrm{a}$

Df

3

Asymp. Sig.

Monte Carlo

Sig.

Sig. $95 \%$ Confidence Interval

$.000 \mathrm{~b}$

Lower Bound .000

Upper Bound .037

$$
\begin{aligned}
& X^{2} \text { cal }=55.73 \\
& X^{2} \text { tab }=7.81 \\
& \mathrm{df}=(4-1)(2-1)=3 \\
& \Theta=\text { level of significance }(95 \%)
\end{aligned}
$$

\section{Decision}

Since the chi-square calculated value of 55.73 is greater than the table value of 7.81 at 3 degree of freedom and with $95 \%$ level of significance, the null hypothesis is hereby rejected. Therefore the alternate hypothesis that states that teamwork, employee engagement does affect institutional performance is accepted.

H0: There is no significant relationship be- 
O. O. OYEDELE AND K. A. MALIK

tween team-leadership and team performance

\section{Chi-Square}

Df

Asymp. Sig.

Sig.

Monte Carlo Sig.

95\% Confidence Interval

$$
\begin{aligned}
& X^{2}{ }_{\text {cal }}=55.73 \\
& X^{2} \quad \text { tab }=7.81 \\
& \mathrm{df}=(4-1)(2-1)=3 \\
& e=\text { level of significance }(95 \%)
\end{aligned}
$$

\section{Decision}

Since the chi-square calculated value of 45.71 is greater than the table value of 7.81 at 3 degree of freedom and with 95\% level of significance, the null hypothesis is hereby rejected. Therefore the alternate hypothesis that states that there is significant relationship between team-leadership and team performance is accepted.

\section{Summary of findings}

Organizations do not exist in a vacuum; they depend on many input factors which human input is highly significant; as it's a factor that integrates other inputs. The optimal performance of this (human) factor is however guaranteed when collectively engaged. O rganizations should always ensure they have policies that will enable their employees work as a team, put in place tools like employee assessment test, and facilitate effective engagement even when slated to function as a team towards the accomplishment of a corporate mission.
Team-leadership and team performance 45.709a

3

.000

$.000 \mathrm{~b}$

Lower Bound .000

Upper Bound .037
Teamwork is becoming increasingly emphasized in corporate practices and educational institutes are not left out, as improved teamwork have resulted in many benefits including improved quality of executed tasks and error reduction. Therefore team training is essential for educational institutions, especially from a perspective of improving interprofessional collaboration and secretariat assignments.

Savvy organizations understand that engaged employees lead to increased productivity, retention, customer loyalty and profitability. An engaged workforce is the key to sustained competitive advantage and accelerated business performance. Employee engagement invokes passion for their work among the employees and drives them to meet and even exceed their expectations. Engaging employees is necessary to make them fall in line with the mission, goals and values of the organization and also to facilitate in settling issues and concerns between the employer 
and the employee.

\section{CONCLUSIONS}

The journey to embrace and entrench effective teamwork and engagement may be fraught with challenges. We have the knowledge, in the form of an everexpanding body of literature extolling the value of teamwork and engagement in improving organizational performance; we now have to transform this knowledge into action.

From the findings of this study, the following conclusions were drawn;

The practice of team-working is and should be embraced by corporate organizations, specifically tertiary institution in O gun state, Nigeria. This is evidenced is the study when the respondents' highest percentage of $64.6 \%$ agreed to the objective that teamwork definitely have positively affects institutional performance.

Results reported also gave a clear message about the importance of staff engagement. In general terms, the more positive the experiences of staff, the better the outcomes. Engagement has many significant associations with employee satisfaction, motivation, work-attitude, as well as staff absenteeism and turnover. The more engaged staff members are, the better the outcomes for the organisation generally. Engagement can be fostered through good staff management; having well-structured appraisals (where clear objectives are set, the appraisal is helpful in improving how the employee does their job, and the employee is left feeling valued by their employer) is particularly important, as is working in a well-structured team (where teams have clear shared objectives, work interdependently and meet regularly to discuss their effectiveness).
This is evidenced is the study when the respondents' highest percentage of $52.2 \%$ agreed to the objective that little or no proper engagement leads to employee ineffectiveness.

Supportive team-leadership is also a key conclusion; as it enhances having good job design - meaningful, clear tasks with some opportunity to be involved in appropriate decision-making. These factors are also linked to employee health, which is also important for engagement: high levels of work pressure and stress can lead to disaffection and disengagement.

Working in well-structured teams with an effective team-leader is a predictor of both individual and collective performance. Employees need to feel they can trust their leaders, managers and the system. This will be influenced by what leaders pay attention to, what they monitor, and what they allocate resources to. It will also be influenced by the criteria for recruitment, selection, promotion and disciplinary action.

Engagement is fostered when there are relatively flat hierarchies, widespread use of rituals and rites to celebrate contributions and success, and where there is consistent celebration of accomplishment and innovation. This is evidenced is the study when the respondents' highest percentage of $74.3 \%$ agreed to the objective that team-leadership definitely have positive effects on team's performance.

FUNAAB as an upcoming conventional tertiary institution have good organizational policies that seems to accommodate teamworking among their employees, irrespective of their age, gender, qualification, cadre, junior or senior staff category, working ex- 


\section{O. O. OYEDELE AND K. A. MALIK}

perience, department or unit, and/ or their colleges. The institution is also in line with the philosophy of employee engagement, which is evidenced by their employee assessment test carried out at necessary intervals. Hence, the institution is said to be doing well and commendable.

\section{RECOMMENDATIONS}

In the light of the forgoing conclusions, the researcher gives the following recommendations; In private/ public (governmental) organizations, such type administrative policies which support team efforts inside the organization should be adapted. In this way overall organizational productivity and effectiveness can be enhanced. It is important to develop such an atmosphere where employees are well satisfied with their jobs and cooperative with each other. In this way, employees will be in position to utilize their full potential in their jobs. The research study strongly recommends that the teamwork activities must exist in the organizational environment in order to enhanced employees' performance. Hence, teamwork training should be integrated into undergraduate synopsis. This could be ascertained by creating (trough policies) incentives for professionals to take up teamwork training

Educators in undergraduate education need to distinguish the teamwork contexts and competencies of team-leading required as academia and which of those are essential for non-academia staff. They need to focus especially on these team contexts that a graduate will encounter and the relevant competencies, while preparing the students with generic competencies applicable to the variety of team contexts in tertiary institutions. The results from this study indicate that these key attributes need to be carefully considered by both tutors and students when teamwork activities are proposed.

Future area for further research should be an in-depth analysis of more public and private organizations to comprehend some other factors contributing towards the employee performance.

Other institutions (private/ public) in the education sector should emulate the FUNAAB team-working initiative in order to continually and effectively meet their corporate obligations. Hence, they should create a platform that gives employees the chance to collectively do challenging works, allow staff to access the needed information, put in place plans that allow staff to reach career goals, access to the needed leadership trainings.

\section{REFERENCES}

Catherine Soanes et al 2006, Oxford Didionary of Current Engish (4thed.). O xford University Press Inc., New York.

Davis, J.H., Mayer, R.C. 2007, An integrative model of organizational trust: Past, Present and Future. Acadamic jaumal of manage ment.

Dionco A. 2011, GuidetoBusiness Reserchand Thesis Writing (2nded.). Rasmed Publications Limited, Ibadan, Nigeri.

Durkheim, E. 1894. The Division of Labour in Society, Free Press, New York.

Employee Engagement: Maximizing O rganizational performance. A study conducted by Right Management 2009) http:// www.right.com/ thought/ leadership / research / Employee - engagement--maximizing-organizational-performance.pdf 
Lucas, R., Lupton, B., Mathieson, H. PeadeandPeformanceLink: UnlokkingtheBladk 2006 Human Resarce Management in an Inter- Box, London, CIPD national Context. London, CIPD .

Saks, A. M. 2006. Antecedents and Consequences

Max Weber 1964. The Theory of Social and Economic Organization, Fortress Press Mulika. 2010. The Impact of Teamwork on Employee Performance in Strategic Management and the Performance Improvement Department of Abu Dhabi Police, UAE of Employee Engagemet. Journal of Managerial Psychology, 21, 600-619

Truss, C., Soane, E., Edwards, C., Wisdom, K., Croll, A., Bumett, J. 2006 Waking Life Employe Attitudes and Engagenert 2006. London, CIPD .

Purcell, J., Kinnie, N., Hutchinson, S., https:/ / en.m.wikipedia.org/ wiki/ Rayton, B., Swart, J. 2003 Undestandingthe systems theory

(Manuscipt received 30thMay 2017; accepted: 20th March 2018). 